\title{
Floor-to-ceiling vertical safety nets
}

\author{
S. Romero, P. Riquelme, R. Irles \& E. Segovia \\ Civil Engineering Department, Alicante University, Spain
}

\begin{abstract}
Of all the accidents caused as a result of human activity, free fall in building construction is the one that attracts most social interest, not only because of the economic cost, but also because of the high cost in human lives, as can be seen from the statistics.

Historically, European governments have made important efforts to regulate the characteristics and use of safety devices, mainly by passing laws and regulations. One of those regulations is currently being developed by AENOR's Spanish Working Group AEN/CTN81/SC2/GT7. At the time of writing, it is still only a draft document.

Numerical tests were performed during the present work using ANSYS finite element software, on different variations (square or diamond geometrical shapes, elasticity, eccentric impact, the material used for the perimeter cables, initial prestressing) of a safety net hit by a $100 \mathrm{~kg}$ ballast with a velocity of almost $6 \mathrm{~m} / \mathrm{s}$. The results are compared to those obtained in previous work for other types of nets, as well as obtaining stress results on the ballast, the net and the anchorages, maximum net deflection, and its consequences on the victim's safety.

By these means, we are trying to advance our understanding of such nets, making it possible to answer questions that have arisen when drafting the new regulation, as described in detail in the paper.
\end{abstract}

Keywords: building, safety, net, fall, impact, stiffness.

\section{Introduction}

If we consider the everyday activities of human beings at work, the construction industry has produced and continues to produce the most serious accidents.

According to Spanish Labour Ministry statistics, if we average out the last 5 years, only taking falls to a different level into account, there are 2,042 serious 
accidents and 114 mortal accidents every year, which equates to $26.74 \%$ of the total number of serious accidents and $13.47 \%$ of the total number of mortal accidents, respectively.

Vertical safety nets on the façades of buildings during the construction stage are used in Spain as an alternative to other safety systems [1,2] to avoid falls to a different level. There are two kinds of such nets: floor-to-ceiling nets that secure the entire void between successive floors, and small nets what secure windows and other minor voids. The size of the net is important because small nets with fixed perimeters are much more rigid than larger ones.

This type of safety nets prevents falls from lesser heights more than other types, such as the ones used between two consecutive floors. Their design and requirements are not defined at present, but the AEN/CTN81/SC2/GT7 Spanish Working Group is drafting a specific regulation [3]. In GT7 requirements inspired by [2] were chosen for this safety system. Then, tests of safety nets with a spherical ballast of $100 \mathrm{Kg}$ are considered, but the height of the fall was restricted to $2 \mathrm{~m}$.

To predict and evaluate certain geometrical and mechanical variables in net behaviour, and the effects on the injured person, several models have been analysed, based on previous research carried out by several of the above mentioned authors in the course of the last 10 years [4-6], using the Finite Elements technique, and simulating the fall of such ballast into the safety net. The models analysed and the results are laid out below, for both large and little nets.

\section{Studies carried out}

\subsection{Floor-to-ceiling nets}

In the first model, a $4 \times 3 \mathrm{~m}^{2}$ net with a square mesh of $10 \times 10 \mathrm{~cm}^{2}$ was studied. There are four possible ways of fixing the net to the entire perimeter:

a) every $50 \mathrm{~cm}$ along its upper and lower sides, leaving the other two sides free

b) every $50 \mathrm{~cm}$ along the entire perimeter

c) every $100 \mathrm{~cm}$ along the entire perimeter

d) every $100 \mathrm{~cm}$ along its upper and lower sides, leaving the other two sides free.

The ballast impacted at the bottom left hand side of the net, in such a way that twelve shots were done on a $50 \times 50 \mathrm{~cm}^{2}$ grid, as shown in Fig. 1.

The data to be obtained in each model are:

-Loads at fixing points, due to impacts $\left(\mathrm{F}_{\mathrm{x}}, \mathrm{F}_{\mathrm{y}}, \mathrm{F}_{\mathrm{z}}\right)$

-Maximum displacement

-Impact factor

-Horizontal movement of the vertical perimeter rope

-Braid movement between fixing points (opening on impact)

-Loads at braids and perimeter rope. 


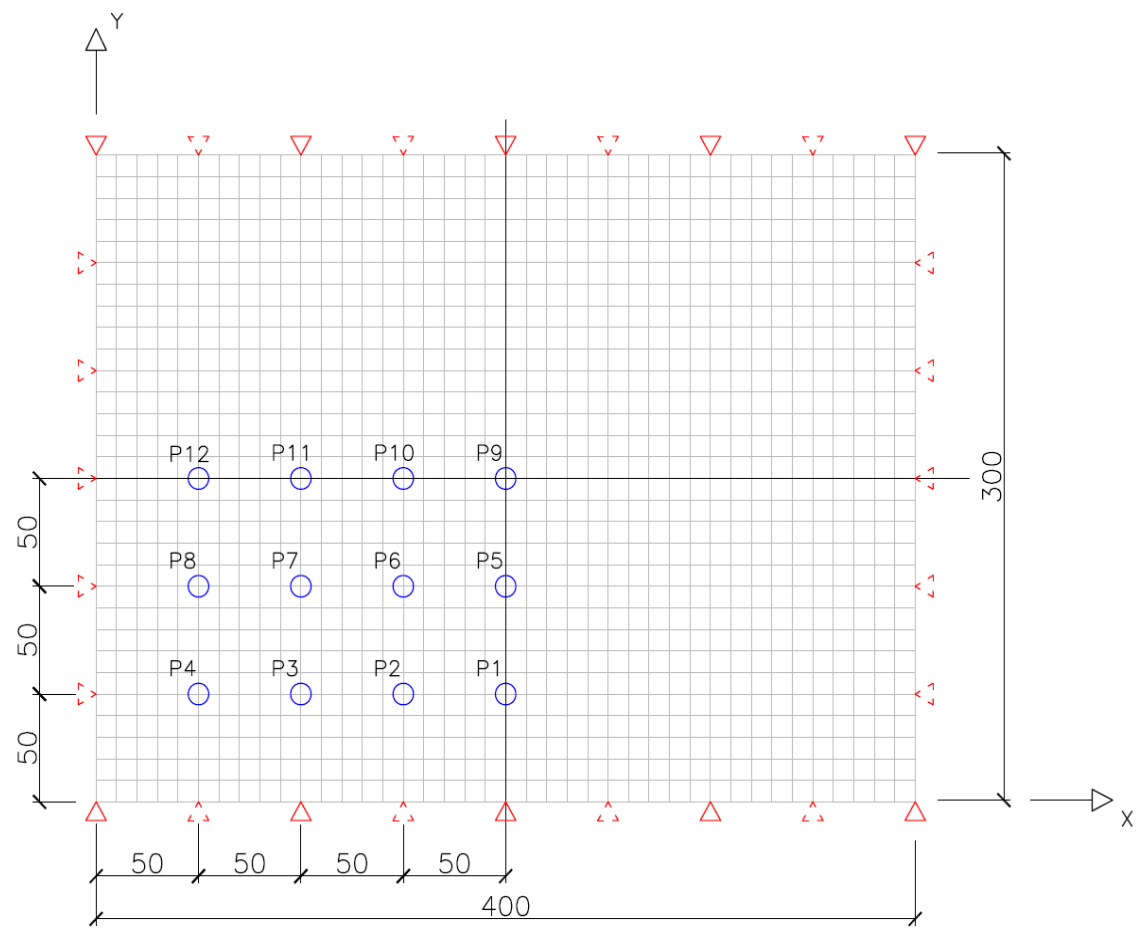

Figure 1: $\quad$ Net dimensions. Impact points.

The model has been developed using ANSYS Finite Element software, employing the following characteristics to recreate the model:

-Transient dynamic analysis

-Net linear elastic behaviour without compression stiffness, with dampening

-Wide displacements and rotations, even with large deformations in the net

-Tension stiffening

-Variable contact between load and net.

With regard to the solid model, the net is shown through linear elements with no resistance to compression, pin-jointed at its ends. This is done in line with a simplified law of behaviour, capable of gathering the ability of energy absorption at the nodes in an "equivalent" way.

Equivalence was adjusted according to available experimental results for $\mathrm{V}$ type nets [6]. Due to the lack of real validation trials, we have assumed the validity for the type of nets studied in this work.

This bilinear law of behaviour for this net (Fig. 2) deviates from the real one [7] mainly on account of the following reasons:

-The tightness of the nodes, whose main effects on energy absorption in our model follow the structural absorption $(\beta)$ response, and on the higher apparent deformability is denoted by the fictitious value of $k_{r}$.

-The large deformations that appear on the net mean that the stress-strain ratio when the net is working under tension, deviates from a straight line. 
Nonetheless, it has been adopted in this analysis, as the calibration for V-type nets showed that, on the whole, it behaves in an equivalent manner to the ones observed in experimental tests.

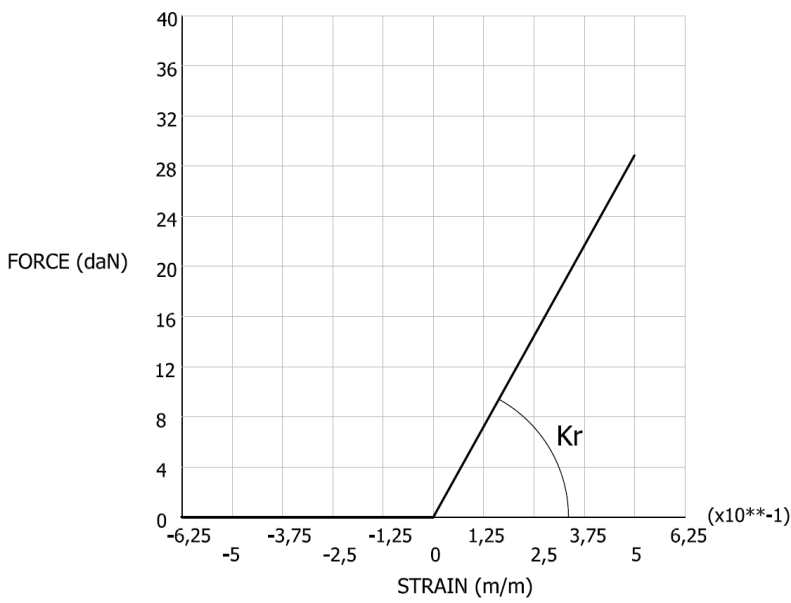

Figure 2: Net behaviour law.

The material that composes the mesh was modelled with LINK10 elements, with a $\beta=0.34$ viscoelastic behaviour, a weight of $0.008 \mathrm{Kg} / \mathrm{m}$, and a stiffness $k_{r}=610 \mathrm{~N}$.

The ballast has been defined as a sphere that does not lose its shape. This sphere is made of area elements, and moves at a constant $6 \mathrm{~m} / \mathrm{s}$ speed. In order to model this, a rigid sphere has been used, together with a (TARGE170) surface. The surface is joined to a contact element (CONTACT173 in this case), which surrounds the solid element to create a contact outline. Finally, certain ballast characteristics must be applied to the sphere though a MASS21-type element.

As this could only be carried out in between surfaces, and in order to make contact between the ballast and the net, it was necessary to create a bindingsurface element with the net that could also keep its unchanging shape characteristics. To do this, a low-stiffness membrane was created and modelled using SHELL41 elements.

\subsection{Small nets}

As in the previous item, for the analysis of small nets we have modelled the impact of a $100 \mathrm{~kg}$ ballast in free fall from a height of $2 \mathrm{~m}$. This supposes a kinetic energy on impact of $2 \mathrm{~kJ}$. The net that suffers the impact is a $1.0 \times 1.0 \mathrm{~m}^{2}$ square (corresponding to a window space) with a $10 \times 10 \mathrm{~cm}^{2}$ mesh size, anchored only at his four corners. Both types of geometry have been analyzed: square mesh (Q) and diamond mesh (D), fig. 3. The modelling of the anchorages has not been considered, assuming it to be rigid. 

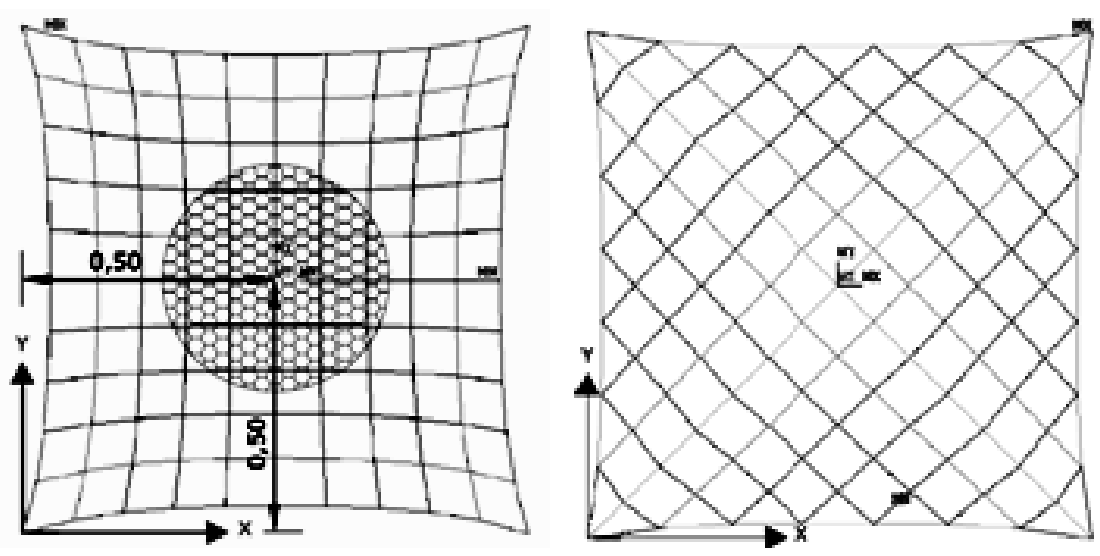

Figure 3: $\quad$ Q and D meshes.

Given the dimensions thereof, all the elements of the net have been considered to be potential points of contact with the spherical ballast.

We have used two types of material for the model: that of the elements of the network and that of the ballast, as in the previous section. For the ballast, only mass is given and used as a rigid element for the impact. In the modelling of the net material, we have considered two types of ropes: the inner meshes and the perimeter ropes. For the perimeter rope a major section was considered. We considered a third case, which consisted of using a perimeter steel cable instead of a rope.

Finite elements of the net are the same as in previous item.

These nets behave in a different manner due to their lesser size. Drawing an analogy with the theory of beams, and observing only the dimensions, the small net corresponds to the short and rigid beam, while the large net corresponds to the long and slender beam.

In order to analyze the sensitive parameters in the numerical model of small nets, a series of control measures were set in each of the models studied. As they were of interest to the standardisation group, the following measures were chosen:

-maximum net deflection in $\mathrm{Z}$ direction

-maximum reaction in a support

-maximum acceleration of the ballast (impact factor) and

-perimeter opening (deflection of the perimeter rope)

In the small-net study models we studied the influence of the following parameters using these control measures:

-mesh geometry

-braid stiffness

-load eccentricity

-perimeter ropes and

-initial braid tension. 


\section{Results}

\subsection{Floor-to-ceiling nets}

Reactions at Anchorage points

Using a net with lateral anchorages causes a significant reduction in reactions compared to not using lateral anchorages. This is even more significant when they are placed closer to each other, where reduction values can be lowered to $50 \%$.

The point of impact creating larger reactions varies also, influenced by the distance between the anchorages. With a gap of $50 \mathrm{~cm}$ between anchorage points, the presence of lateral anchorages produces an increase of the strip where maximum reactions are produced, from the centre point of a lateral to a-meterwide strip along that lateral.

With a gap of $1 \mathrm{~m}$ between anchorage points, when lateral fixing points are used, they move the maximum reaction to the corner. It seems that it is the use of a smaller net surface to distribute the loads, together with a greater distance between the anchorage points that makes it more difficult for the loads to be distributed, than ones which are closer together.

The greatest reaction value is $2377 \mathrm{~N}$, for an impact in position 8, with free laterals and anchorages every $100 \mathrm{~cm}$.

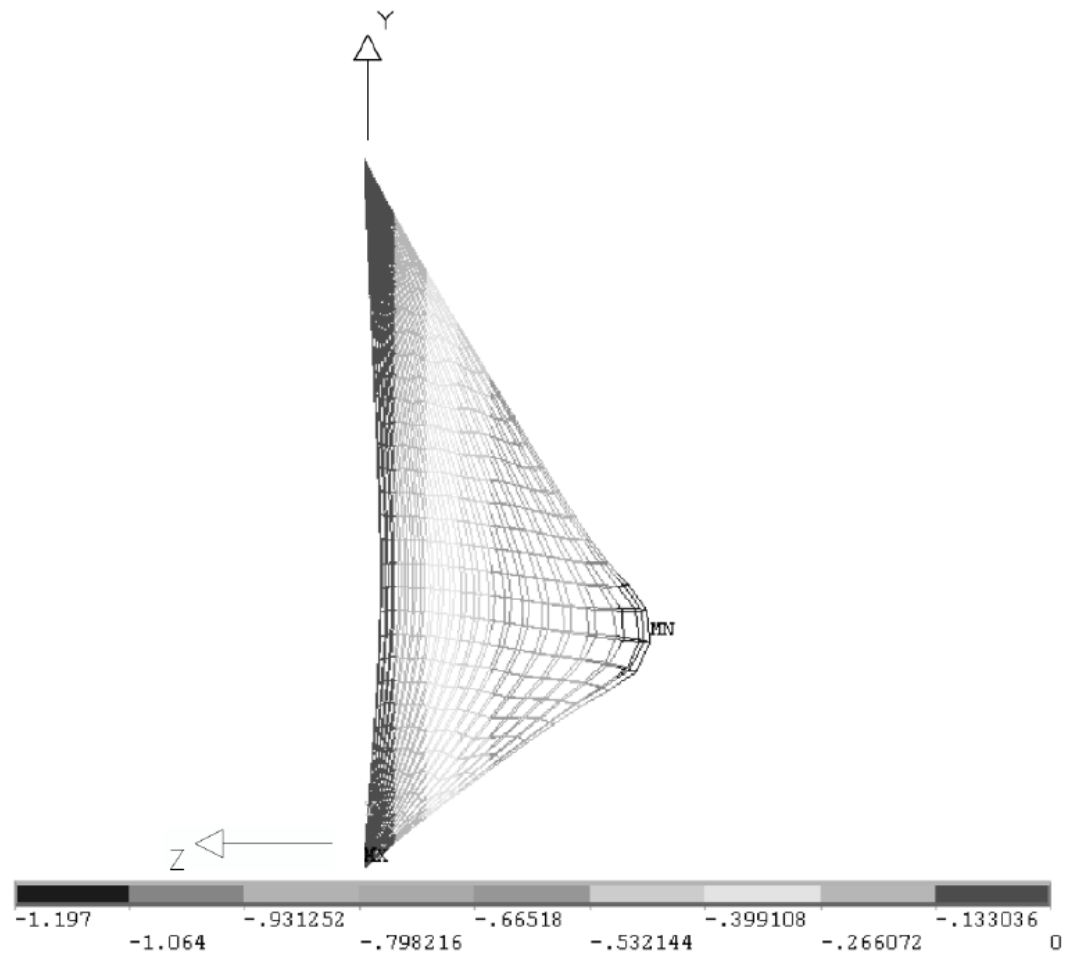

Figure 4: $\quad$ Maximum displacement for impact in position 5 (meters). 
3.1.1 Maximum displacement (fig. 4) The points of impact with maximum and minimum displacement are the centre and the corner of the net respectively, in every case. The maximum displacement is $140 \mathrm{~cm}$, obtained from an impact at the centre of the net, an anchorage distance of $100 \mathrm{~cm}$ and free laterals. The minimum displacement is $85 \mathrm{~cm}$, in the case of an impact at the corner, an anchorage distance of $50 \mathrm{~cm}$ and fixed laterals.

Regardless of the distance between the anchorages, using net laterals produces a small reduction of the displacement values (about $10 \mathrm{~cm}$ ) and an increase in the difference between the maximum and minimum values. However, with a $100 \mathrm{~cm}$ distance the values obtained are about $10 \mathrm{~cm}$ greater than those obtained with a distance of $50 \mathrm{~cm}$.

3.1.2 Acceleration and impact factor The maximum deceleration suffered by the injured party, remains almost constant when the distance between anchorages is increased, reaching values of 3 to $4 \mathrm{~g}$, which is more moderate when compared with recommendations. In the case of lateral anchorages, maximum values increase, the greater the distance ( 4 to $5 \mathrm{~g}$ ).

The maximum and minimum deceleration points coincide with the points of minimum and maximum displacement, respectively. The highest deceleration value is $4.9 \mathrm{~g}$, registered by impacts around the corner area.

3.1.3 Opening between anchorages and the bottom side of the net The opening between the net and the border of the framework does not vary significantly when the location of the lateral anchorages is changed. Only a variation with a higher separation between the anchorages is detected, and the displacement value doubles when the distance between anchorages is in turn doubled.

The points of impact that cause greater openings are those situated close to the bottom side of the net, at the point of anchorage. The biggest opening obtained was one of $0.408 \mathrm{~m}$, for impact position number 2 and an anchorage distance of $100 \mathrm{~cm}$. This value could allow a person to fall, so it is unacceptable.

3.1.4 Opening at the lateral side of the net In cases where no lateral anchorages are available, the movement of the perimeter rope is not affected by increasing the distance between the other anchorages. The maximum opening we observed was $0.670 \mathrm{~m}$, and it was obtained at the centre of the lateral side for impact position number 12 . When there the net is not continuous at any side, this value is high enough as to allow a medium-size person to fall through the hole. As a result, if there is no such continuity, it will be necessary to anchor the net at the sides.

3.1.5 Loads at the braids and perimeter rope The maximum value of loads at the braids does not change when the anchorages are located at the sides of the net; it only increases when the distance between them is modified.

In the case of the perimeter rope, placing the lateral anchorages every $50 \mathrm{~cm}$ causes a significant reduction in loads of up to $55 \%$, and up to $17 \%$ when the separation is $100 \mathrm{~cm}$. 
The points of impact that give rise to higher loads in the braids are the ones in the central area, close to the bottom of the net. For the perimeter rope, these points are the ones closest to it, and, depending on whether there are lateral anchorages or not, its central area or the corner area, respectively.

The highest load value for the perimeter rope was $2261 \mathrm{~N}$, and it was recorded in the corner area with impact at position number 8 , anchorages at 100 $\mathrm{cm}$, and free-moving laterals. For the braids, the maximum value was $647 \mathrm{~N}$, recorded at impact position 1 and with anchorages every $50 \mathrm{~cm}$ along all four sides.

These values are lower than indicated by Saiz et al. [4], where the values for the break resistance of braids are $1156 \mathrm{~N}$ - including the reduction when using a double cloth knot.

\subsection{Small nets}

We have obtained the following data from the numerical models studied:

-They are sensitive to geometrical changes, from square mesh (Q) to diamond mesh (D). The maximum deflections of the models using $\mathrm{D}$ meshes present values $12 \%$ less that the models with $\mathrm{Q}$ meshes, and there is a linear correlation between both groups of deformations (fig. 5). In D net it seems that the response is more immediate and this reaction speed can generate lower top deflections and lower top reactions. In turn, this immediacy can be justified by the response of the central braids which sit directly on the support points.

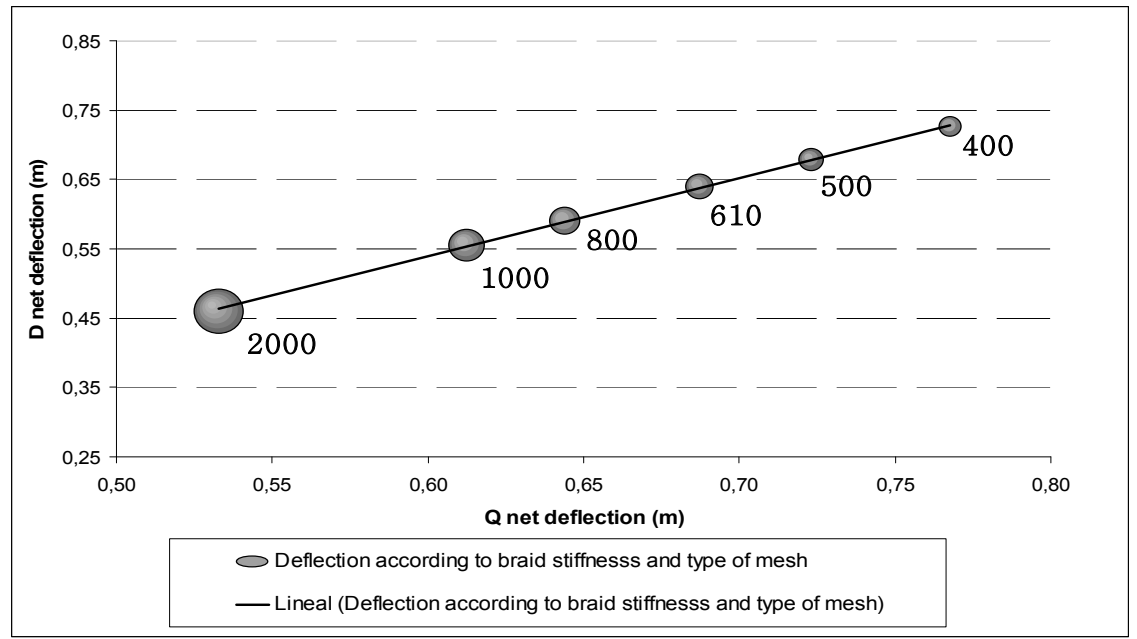

Figure 5: Q net versus D net deflections and braid stiffness.

-The increment of braid stiffness gives us the expected sensitivity (the stiffness of the whole net increases). Net deflection decreases and maximum ballast acceleration increases. The reaction at the net supports shows a quasi linear relation (fig. 6). 


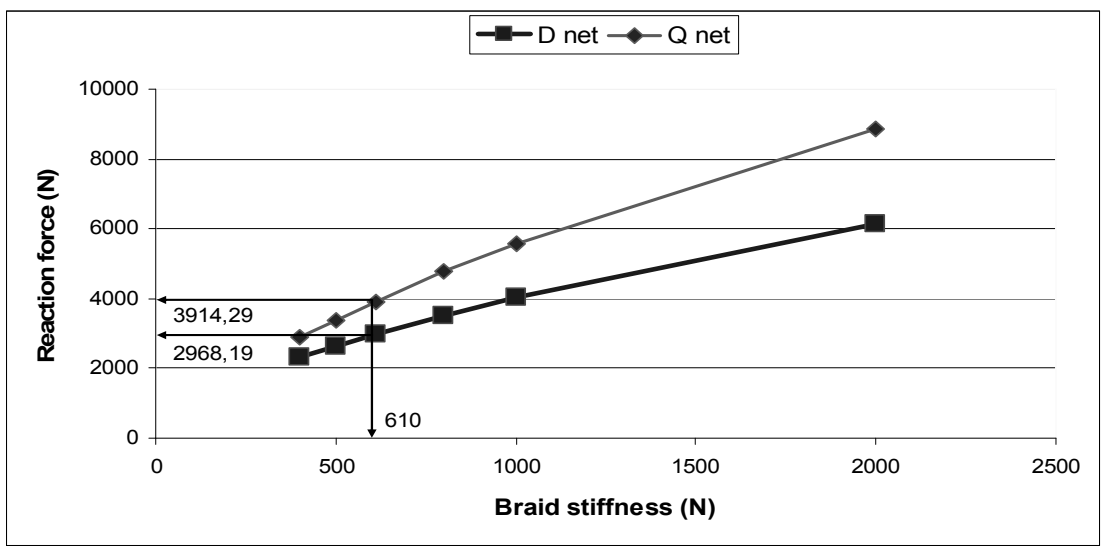

Figure 6: Reaction force versus braid stiffness.

-The eccentricity of the load is a very sensitive parameter in the models used to measure reactions at both the supports and the tension in the perimeter ropes. As opposed to the central impact, the maximum eccentricity provokes increases of $45 \%$ in the maximum tension of the perimeter rope. In addition, the eccentricity causes a modification in the composition of the force of the reaction (fig. 7) increasing the $Z$ value (normal direction to the impact), decreasing the component of the direction of the eccentricity, and increasing the result. The response for an eccentric impact generates a greater and more rapid reaction since the forces of the impact are transferred at greater speed to the support.

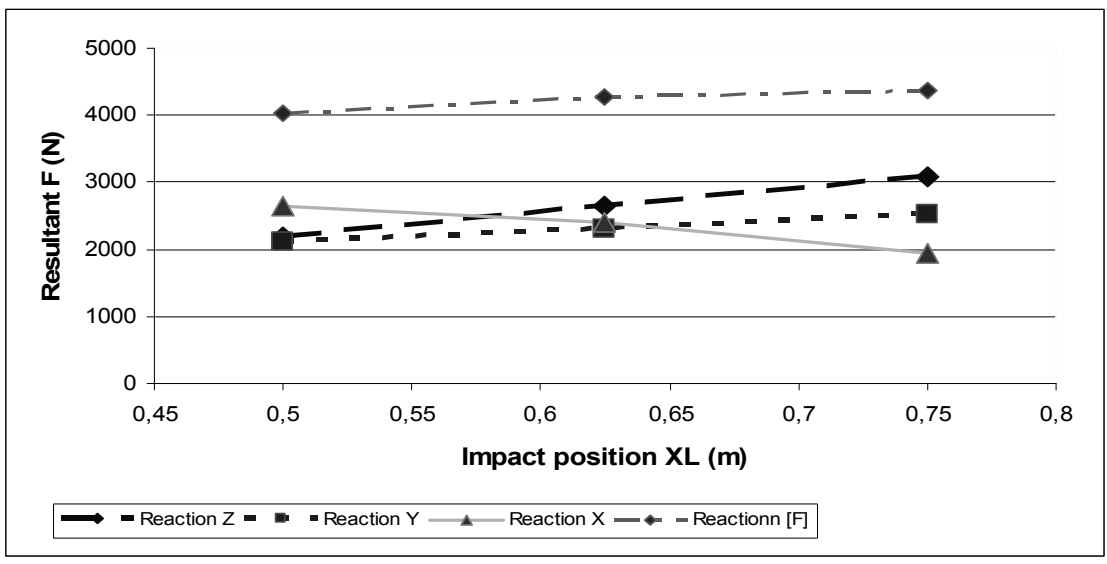

Figure 7: Reaction force versus eccentricity.

-For the perimeter ropes, in the models using steel cables along the horizontal sides, we observe a reduction in deflection, irrespective of the braid stiffness (table 1). The reactions in the supports remain distorted when steel perimeter cables are used: these raise the values considerably (10 times). 
Table 1: $\quad$ Maximum deflection of $\mathrm{Q}$ and $\mathrm{D}$ nets versus stiffness.

\begin{tabular}{|c|c|c|c|c|c|c|}
\cline { 2 - 7 } \multicolumn{1}{c|}{} & \multicolumn{3}{c|}{ Q NET } & \multicolumn{3}{c|}{ D NET } \\
\cline { 2 - 7 } \multicolumn{1}{c|}{} & With cable & Without & Difference & With cable & Without & Difference \\
\hline $\begin{array}{c}\text { Link 10 } \\
\text { stiffness } \\
(\mathrm{N})\end{array}$ & $\begin{array}{c}\text { Max. } \\
\text { deflect. } \\
(\mathrm{m})\end{array}$ & $\begin{array}{c}\text { Max. } \\
\text { deflect. } \\
(\mathrm{m})\end{array}$ & $(\mathrm{m})$ & $\begin{array}{c}\text { Max. } \\
\text { deflect. } \\
(\mathrm{m})\end{array}$ & $\begin{array}{c}\text { Max. } \\
\text { deflect. } \\
(\mathrm{m})\end{array}$ & $(\mathrm{m})$ \\
\hline 610 & 0.566 & 0.687 & 0.121 & 0.578 & 0.639 & 0.062 \\
\hline 800 & 0.522 & 0.644 & 0.122 & 0.534 & 0.591 & 0.057 \\
\hline 1000 & 0.490 & 0.612 & 0.122 & 0.501 & 0.555 & 0.053 \\
\hline 2000 & 0.409 & 0.533 & 0.123 & 0.416 & 0.461 & 0.044 \\
\hline
\end{tabular}

The perimeter openings depend on the perimeters ropes; with steel cables they are practically void and with perimeter textile ropes, at worst, they reach values of $0.20 \mathrm{~m}$., a space which is not great enough to imply any risk of a person falling.

-The initial tension in the models, as well as the use of cables as opposed to textile ropes (for Q net), shows two characteristics, one of them more significant than the other. The first is the lower maximum deflection in models with initial tension, the second is a slight decreasing tendency (table 2 and fig. 8 ) in the impact factor (maximum acceleration suffered by the ballast).

Table 2: $\quad$ Impact factors for $\mathrm{Q}$ and $\mathrm{D}$ nets versus stiffness.

\begin{tabular}{|c|c|c|c|c|c|c|}
\cline { 2 - 7 } \multicolumn{1}{c|}{} & \multicolumn{3}{c|}{ Q NET } & \multicolumn{3}{c|}{ D NET } \\
\cline { 2 - 8 } & $\begin{array}{c}\text { With } \\
\text { cable }\end{array}$ & Without & Difference & $\begin{array}{c}\text { With } \\
\text { cable }\end{array}$ & Without & Difference \\
\hline $\begin{array}{c}\text { Link 10 } \\
\text { stiffness } \\
(\mathrm{N})\end{array}$ & $\begin{array}{c}\text { Impact } \\
\text { factor } \\
(\mathrm{g})\end{array}$ & $\begin{array}{c}\text { Impact } \\
\text { factor } \\
(\mathrm{g})\end{array}$ & $(\mathrm{g})$ & $\begin{array}{c}\text { Impact } \\
\text { factor } \\
(\mathrm{g})\end{array}$ & $\begin{array}{c}\text { Impact } \\
\text { factor } \\
(\mathrm{g})\end{array}$ & $(\mathrm{g})$ \\
\hline 610 & 6.705 & 7.545 & 0.840 & 6.661 & 6.317 & -0.344 \\
\hline 800 & 7.585 & 8.754 & 1.169 & 7.543 & 7.121 & -0.422 \\
\hline 1000 & 8.388 & 9.840 & 1.452 & 8.317 & 7.820 & -0.497 \\
\hline 2000 & 11.375 & 13.673 & 2.298 & 10.899 & 10.036 & -0.863 \\
\hline
\end{tabular}

The lower maximum deflection would be explained by the greater stiffness of the loaded system; the minor impact factor might be explained by the greater initial response of the loaded system. The initial accelerations that the ballast suffers reduce the peak of maximum acceleration (fig. 8). In prestressed models, the maximum deflection is reached earlier, and it is less, with a lower impact factor. 


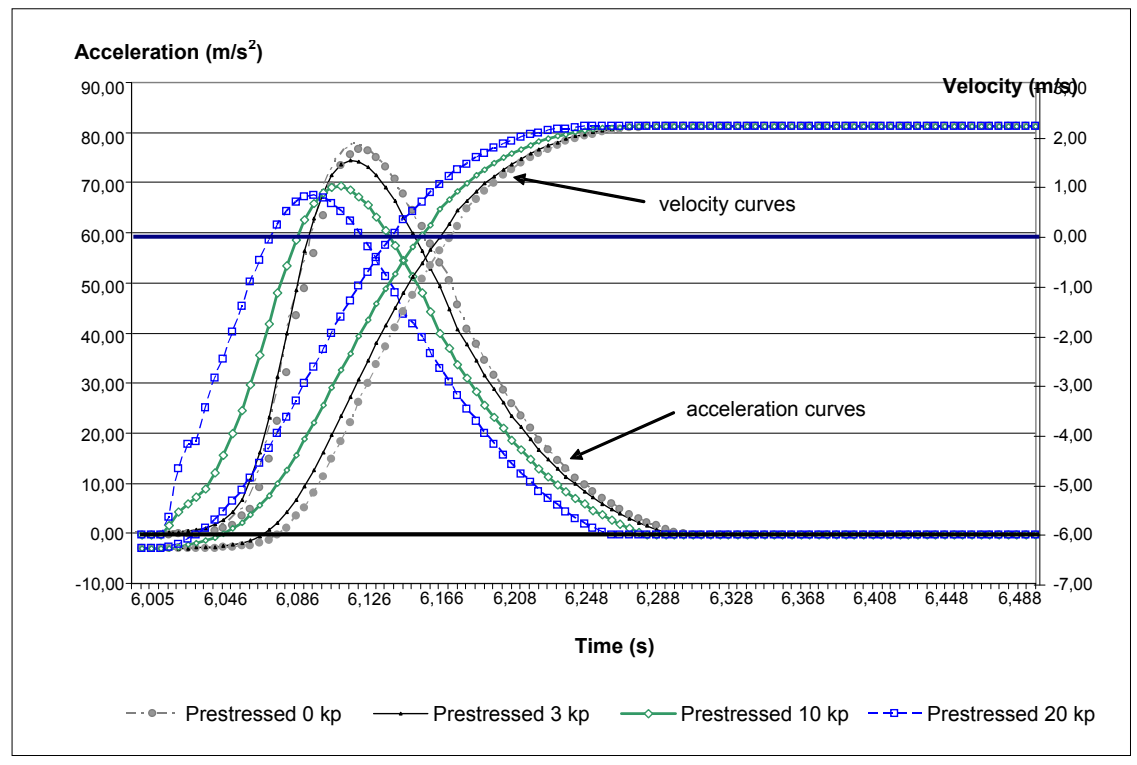

Figure 8: $\quad$ Speed and acceleration curves.

\section{Conclusion}

Floor-to ceiling vertical safety nets are a possible solution to avoid people falling in buildings at the construction stage, when working between floors. In this case the kinetic energy of possible victims reaches moderate values, and the use of such nets, more rigid than other types of net, leads to acceptable impact factors.

Net deflection varies from about 0.75 to $1.5 \mathrm{~m}$, depending on the point of impact in big nets. For small ones only the first value applies.

Accelerations suffered by injured people are about $4-5 \mathrm{~g}$ in the case of big floor-to-ceiling nets and about $7-8 \mathrm{~g}$ for small nets $\left(1 \times 1 \mathrm{~m}^{2}\right)$.

Results show that net and perimeter rope tensions are acceptable in nets currently being used. Reaction values for anchorage points were also calculated and they are also acceptable using the adequate devices currently in use.

For big nets it has been proven that a maximum distance of $50 \mathrm{~cm}$ between anchorages is required to avoid openings along the perimeter of the net, which lead to the risk of falling. However, small nets for windows (around $1 \times 1 \mathrm{~m}^{2}$ ) can be anchored only at corners and there are no dangerous openings, but reaction values increase moderately at this point. For small nets, initial tension leads to lower deflection but also to a lower impact factor.

\section{References}

[1] EN 13374 Temporary Edge Protection Systems. Product specification, test methods. December 2004. 
[2] EN 1263 Safety Nets. Part 1: Requirements, Test methods. 1997

[3] Pr-UNE PNE 81651 Redes de cierre vertical. Internal document of AEN/CTN81/SC2/GT7. 2010. (In Spanish).

[4] Saiz, J.; Irles, R.; Arcenegui, G.A.; Naharro, M., Security Nets in Construction. Alicante University. D.G.T. (Government of Valencia), Alicante (Spain), 1997. (In Spanish).

[5] Saiz, J., García, R.; Irles, R.; Montava, I; Pey, J. "Concerning Security Nets". Health and Work No 104 (INSHT), Spain, 1994. (In Spanish).

[6] Segovia Eulogio, Enrique; Irles Más, Ramón; González Sánchez, Antonio, Maciá Mateu, Antonio; Pomares Torres, Juan Carlos. "Vertical Security nets in building construction II". Informes de la Construcción, volume 59, $\mathrm{n}^{\mathrm{o}}$ 505, 37-51, January-March 2007. (In Spanish).

[7] Paureau, J.: "Filets carrés de sécurité en grandes nappes en polyamide 6. Performances. Règles de pose”. Institut National de Recherche et Sécurité, Vandoeuvre-les-Nacy (France), 1987. (In French). 